\title{
Article \\ Reproducibility of Stress Wave and Electrical Resistivity Tomography for Tree Assessment
}

\author{
Steffen Rust (D)
}

check for

Citation: Rust, S. Reproducibility of Stress Wave and Electrical Resistivity Tomography for Tree Assessment. Forests 2022, 13, 295. https:/ / doi.org/10.3390/f13020295

Academic Editor: Brian Kane

Received: 31 December 2021

Accepted: 8 February 2022

Published: 12 February 2022

Publisher's Note: MDPI stays neutral with regard to jurisdictional claims in published maps and institutional affiliations.

Copyright: (c) 2022 by the author. Licensee MDPI, Basel, Switzerland. This article is an open access article distributed under the terms and conditions of the Creative Commons Attribution (CC BY) license (https:// creativecommons.org/licenses/by/ $4.0 /)$.
Faculty of Resource Management, University of Applied Sciences and Arts, 37077 Göttingen, Germany; steffen.rust@hawk.de

\begin{abstract}
Background: Tomography is widely used in tree risk assessment and forest ecology. Tomograms should be accurate, repeatable and comparable between consecutive measurements. This is the first longitudinal study addressing reproducibility over a period of several years and the key factors influencing it, from raw data to final tomograms. (2) Methods: Trees were either repeatedly measured by the same researcher over periods of hours to months, by different researchers using either the same or a new installation of the same equipment, or with different tomographs. (3) Results: Overall, differences between tomograms were small and without impact on the assessment of the safety of the tree. Between initial and follow-up measurements after 2 to 5 years, the coefficients of correlation of stress wave velocity ranged from 0.75 to 0.96 , those of loss in section modulus estimated from tomograms ranged from 0.82 to 0.93 . The coefficient of correlation of repeated sapwood area estimates with electrical resistivity tomography was 0.97 . The major cause of deviations was variation in the sensor positions between repeated tomographies, and, for electrical resistivity tomography, variation of temperature. (4) Conclusion: Provided that sensor positions are accurately recorded and documented, tomograms can reliably be repeated by different assessors over periods of years. Assessments based on complex calculations like loss of section modulus should be treated with caution, because they accumulate and amplify all sources of variation.
\end{abstract}

Keywords: tree risk assessment; stress wave tomography; electrical resistivity tomography

\section{Introduction}

Property owners and government agencies have a legal duty of care for their trees and thus have to manage risks related to these trees. A central part of tree risk management is tree risk assessment. The risk of the vast majority of trees can be assessed visually during a basic assessment, but when the likelihood of failure remains uncertain after a visual inspection, a number of tools can be used for an advanced assessment to measure the extent of decay, loss of strength, or anchorage. Tomographs are such tools that have been widely used in tree risk assessment and research in urban forestry in recent years (e.g., [1-5]). They are used to map internal decay non-destructively. Sonic tomographs (SoT) measure the time-of-flight of signals $(t)$ to produce a map of apparent absolute or relative stress wave velocity (v), which will reveal areas of sound wood, if they can be traversed by stress waves on a straight path from one sensor to another. Electrical resistivity tomography (ERT) is a method to determine the spatial distribution of electric resistivity $(\rho)$ non-destructively. In trees, results mainly correlate with ion and moisture content of the wood (e.g., [2-4]) and, to a lesser degree, wood temperature. In urban tree risk assessment ERT is used to aid the interpretation of results from SoT [6].

In tree risk assessment, tomograms are usually assessed with thresholds of residual wall thickness $[7,8]$ or used in quantitative mechanical evaluations of the tomogram in terms of the section modulus $(Z)$ or its resistance to bending [9]. Because the contribution of any part of the cross-section to the second moment of area increases with the square of 
its distance to the neutral axis of the stem (s. Equation (2)), even apparently small variations in the input to these calculations may result in large variation in their result $[10,11]$.

A source of such variations within tomograms common to both methods is the distance between measurement points. Stress wave velocity is calculated from the time-of-flight (measured by the sensors), and the distance between those sensors (measured by the operator), while in electrical resistivity tomography, apparent resistivity is estimated from resistance between electrode pairs and electrode positions. A further source of variation between tomograms are the changes in sensor position that are unavoidable when measurements are repeated after several years, possibly by different operators.

Seasonal and diurnal changes in wood moisture and temperature could add further variation to tomograms. However, effects of wood moisture on $v$ and resulting SoT of living trees are generally low [12-15] and the impact of declining temperature on stress wave velocity and tomograms is negligible as long as wood is not frozen [16].

Stem electrical resistivity, on the other hand, changes significantly with temperature $[17,18]$ and seasonally changing resistivity has been described for Fagus sylvatica by [19], who found different pattern of change in sap wood and heart wood. Similarly, wood moisture content has a significant effect on $\rho$ and resulting tomograms $[17,18]$.

When technical devices support decision making in tree risk management, the degree of uncertainty of their results should be known. Moreover must results of measurements in tree risk assessment be reproducible, especially for controversial trees, which might be assessed by different consultants for opposing clients. Even when trees are deemed safe by a consultant, the report will often advise making follow-up measurements after a period of some years. In these cases, it will be important that consultants can distinguish between effects of measurement uncertainty and a progression of decay.

So far, the different factors relevant to producing comparable tomograms have rarely been studied quantitatively and research concentrated on the effects of changes in wood temperature and moisture. No previous study has investigated the level of variation inherent in measurements of the loss of load bearing capacity $\left(Z_{\text {Loss }}\right)$ repeated over the course of years. Here, the complete process from the acquisition of raw data (sensor positions, stress wave travel times, electrical resistivities) to the mechanical evaluation of tomograms in terms of loss in section modulus, is analyzed for the first time. This investigation will help risk assessors and tree pathologists alike to evaluate differences between tomograms made by different operators at different times.

\section{Materials and Methods}

\subsection{Sites and Trees}

Several groups of mature and ancient trees were measured, growing along urban roads, in parks and forests, or in open landscapes (Table 1). Their diameters ranged from just over $30 \mathrm{~cm}$ to more than $2 \mathrm{~m}$. The species included Fagus sylvativa L., Picea abies (L.) Karst., Quercus robur L., and Acer pseudoplatanus L. Climate across Germany is temperate. At site TG $\left(52.3626^{\circ} \mathrm{N}, 9.833^{\circ} \mathrm{E}\right)$, mean temperature in the period studied (2015-2020) was $10.8{ }^{\circ} \mathrm{C}$, annual rainfall was $593 \mathrm{~mm}$, at site $\mathrm{KF}\left(51.52574^{\circ} \mathrm{N}, 10.01636^{\circ} \mathrm{E}\right)$, mean temperature in the period studied (2017-2021) was $10.1^{\circ} \mathrm{C}$, annual rainfall was $592 \mathrm{~mm}$, and at site PA1 $\left(51.509^{\circ} \mathrm{N}, 9.9809^{\circ} \mathrm{E}\right)$, mean temperature in the period studied (February 2021-November 2021) was $11.7^{\circ} \mathrm{C}$, rainfall was $483 \mathrm{~mm}$.

\subsection{Tomography}

Stress wave tomograms were made with a Picus ${ }^{3}$ sonic tomograph (argus electronic $\mathrm{GmbH}$, Rostock, Germany), electrical resistivity tomograms were made with either a Picus Treetronic ${ }^{3}$ (argus electronic GmbH, Rostock, Germany) or a Geotom (GEOLOG2000 System- und Meßtechnik, Starnberg, Germany).

Briefly, sonic tomographs measure the time-of-flight of signals excited by hammer blows, and recorded with 8-24 sensors attached with magnets to nails in one plane around the stem. The nails have to be in contact with the outermost growth ring. The apparent 
stress wave velocity $(v)$ is calculated from the time and distance data measured at the tree, assuming a straight path of the stress waves, because their true path is unknown. Electrical resistivity tomography can use the same nails as electrodes to inject and measure a current. Data were collected using a dipole-dipole configuration. Sensor positions were recorded with an electronic caliper (Picus Caliper, argus electronic, Rostock, Germany) using a system of triangulation.

Tomograms were produced with the software Picus Q74 (argus electronic $\mathrm{GmbH}$, Rostock, Germany). ERT inversion is based on [20,21], while the SoT-algorithm has not been documented by the company.

\subsection{Treatments}

The analyzed experimental factors were:

- number of operators: either one, two or three

- installation of nails: either use the same nails, or install new ones

- $\quad$ time between repeated measurement: minutes, weeks, or years

- devices: measurements repeated with the same or a different product

Trees at sites PA2 and AP were felled to take images of the cross-sections of the tomographic measurements. At site AP, drilling resistance profiles (Resistograph, Rinntech, Heidelberg, Germany) were used to assist the delineation of decay in the stem cross-sections [22].

At site PA1, soil $\mathrm{pF}$ and temperature were recorded with Picus Tension sensors (argus electronic $\mathrm{GmbH}$, Rostock, Germany). Temperature data of the nearest official weather station (station code 1691) were used for sites KF and PA1 [23].

Table 1. Sites, trees, and treatments.

\begin{tabular}{|c|c|c|c|c|c|c|c|c|c|}
\hline Site & Location ${ }^{1}$ & Type & Species & n & Operators & $\begin{array}{c}\text { Different } \\
\text { Nails }\end{array}$ & $\begin{array}{l}\text { Different } \\
\text { Devices }\end{array}$ & Season & Measurements \\
\hline KF & Göttingen & open field & $\begin{array}{c}\text { Fagus } \\
\text { sylvativa } \mathrm{L} .\end{array}$ & 47 & 3 & $x$ & & $\begin{array}{l}\text { Sep. 2017, } \\
\text { Sep.-Dec. } \\
\text { 2019, Mar. } \\
2021\end{array}$ & SoT, ERT \\
\hline PA1 & Göttingen & forest & $\begin{array}{l}\text { Picea abies } \\
\text { (L.) Karst. }\end{array}$ & 20 & 1 & & $\mathrm{x}$ & $\begin{array}{c}\text { Feb.-Nov. } \\
2021\end{array}$ & ERT \\
\hline TG & Hannover & park & $\begin{array}{l}\text { Quercus } \\
\text { robur L. }\end{array}$ & 26 & 2 & $\mathrm{x}$ & & $\begin{array}{l}\text { Oct. 2015, } \\
\text { Oct. } 2020\end{array}$ & SoT, ERT \\
\hline $\mathrm{AP}$ & Heidelberg & roadside & $\begin{array}{l}\text { Acer pseudo- } \\
\text { platanus } \\
\text { L. }\end{array}$ & 5 & 3 & $x$ & & May 2021 & SoT, ERT \\
\hline PA2 & Heidelberg & forest & $\begin{array}{l}\text { Picea abies } \\
\text { (L.) Karst. }\end{array}$ & 7 & 3 & & & Sep. 2014 & SoT \\
\hline
\end{tabular}

${ }^{1}$ All sites in Germany.

\subsection{Statistical Analyses}

The area of the tomogram $A$, its section modulus $Z$, and the maximum loss of $Z$ (Equations (1)-(4), [9,10,24]) were further analyzed with the Plugin BoneJ for ImageJ [25-27]. ImageJ was also used to analyze images of cross-sections of felled trees. R Statistical Software [28] with package nlme [29] were used for statistical analyses. Linear mixed-effect models were used to account for random effects like repeated measurements [30]. Reported coefficients of correlation are robust estimates [31]. Statistical details of model results are reported in Appendix A Tables A1-A16.

$$
\begin{gathered}
\lambda=\frac{\sum y d A}{\sum d A} \\
I=\sum(y-\lambda)^{2} d A \\
Z=\frac{I}{\max (\lambda)}
\end{gathered}
$$




$$
Z_{\text {Loss }}=\frac{Z_{\text {solid }}-Z_{\text {decayed }}}{Z_{\text {solid }}}
$$

where $\lambda$ is the distance between the edge of the tomogram and the neutral axis, $y$ is the distance between the horizontal line and a finite small area $(d A)$ which was taken as a pixel in the white area in the binarized image [24]. $I$ and $Z$ are the moment of inertia and the section modulus.

Parameters analyzed were:

- $\quad$ Distance between sensors/electrodes, $d$

- Cross-sectional of the tomogram, $A$

- $\quad$ Stress wave travel-time, $t$

- Stress wave velocity, $v$

- $\quad$ Loss in section modulus, $Z_{\text {Loss }}$

- $\quad$ Electrical resistance, $\Omega$

- Electrical resistivity, $\rho$

To account for heartwood, central cavities, and the variation of sap and air temperature, ERT-data were split into central, middle, and edge third by area.

\section{Results}

\subsection{Stress Wave Travel Times, Stress Wave Velocity, and Sensor Positions}

Tomograms, even when measured by different operators some years apart, were generally very comparable (Figure 1).

All follow-up measurements correlated closely with the original data (Figure 2). The closest correlation was found for stem cross-sectional area $A$, which results from the triangulation of sensor positions, and stress wave travel times $t(0.92 \leq r \leq 0.99)$. Slight variation in stress wave travel times and sensor distances resulted in a modest scatter of stress wave velocity ( $r \geq 0.75$, Figure 2$)$. A similar scatter is found in the most complex parameter $Z_{\text {Loss }}(r \geq 0.82$, Figure 2$)$, which integrates all measurements of sensor positions and stress wave travel time into one single parameter.

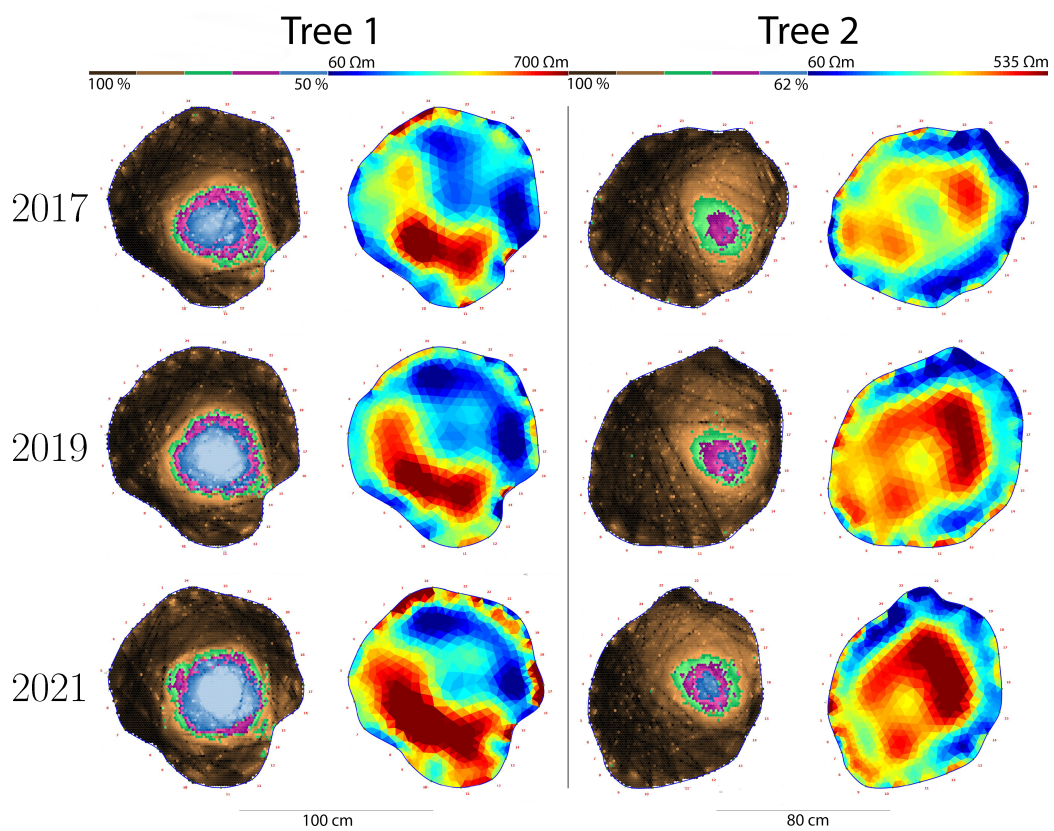

Figure 1. SoT (1. and 3. column) and ERT (2. and 4. column) of two beech trees measured three times by different operators using slightly different sensor positions every time (site KF).

Measured sensor distances changed significantly by $2.5 \%$ to $3.2 \%$ when tomography was repeated after 2 to 5 years at sites KF $(p<0.001)$ and TG $(p=0.004)$. In the same data 
sets, mean stress wave travel times $t$ and velocities $v$ had changed significantly $(p<0.001)$ by $4 \%$ to $11 \%$. The significant change at site KF occurred from 2017 to 2019, with no difference between measurements in 2019 and 2021. Mean $Z_{\text {Loss }}$ at site KF increased by 19\% between 2017 and 2019, and fell by 23\% over the following 2 years below the level measured in 2017. At site TG the mean difference in $Z_{\text {Loss }}$ after 5 years was $7 \%$. All changes in $Z_{\text {Loss }}$ were not significantly different from 0 .

There was a small but significant interaction effect of operator and sensor distance on absolute stress wave velocity, even when using the same nails (site PA2, linear mixedeffects model, $p<0.0125)$. The three operators measuring 7 cross-sections in $P$. abies at PA2 differed between $0.1 \%$ and $3 \%$ from the mean travel times. In the experiment where operators placed new nails individually (AP), there was no significant operator effect on stress wave travel time (linear mixed-effects model, $p=0.53$ ). Figure 3 illustrates the proximity of data measured by different operators at the same tree. The area of decay measured with SoT did not differ significantly between operators (Figure 3), independent of whether nails were re-used or placed anew. Nonetheless, a few individual results were clearly wrong from the point of view of a tree assessor.
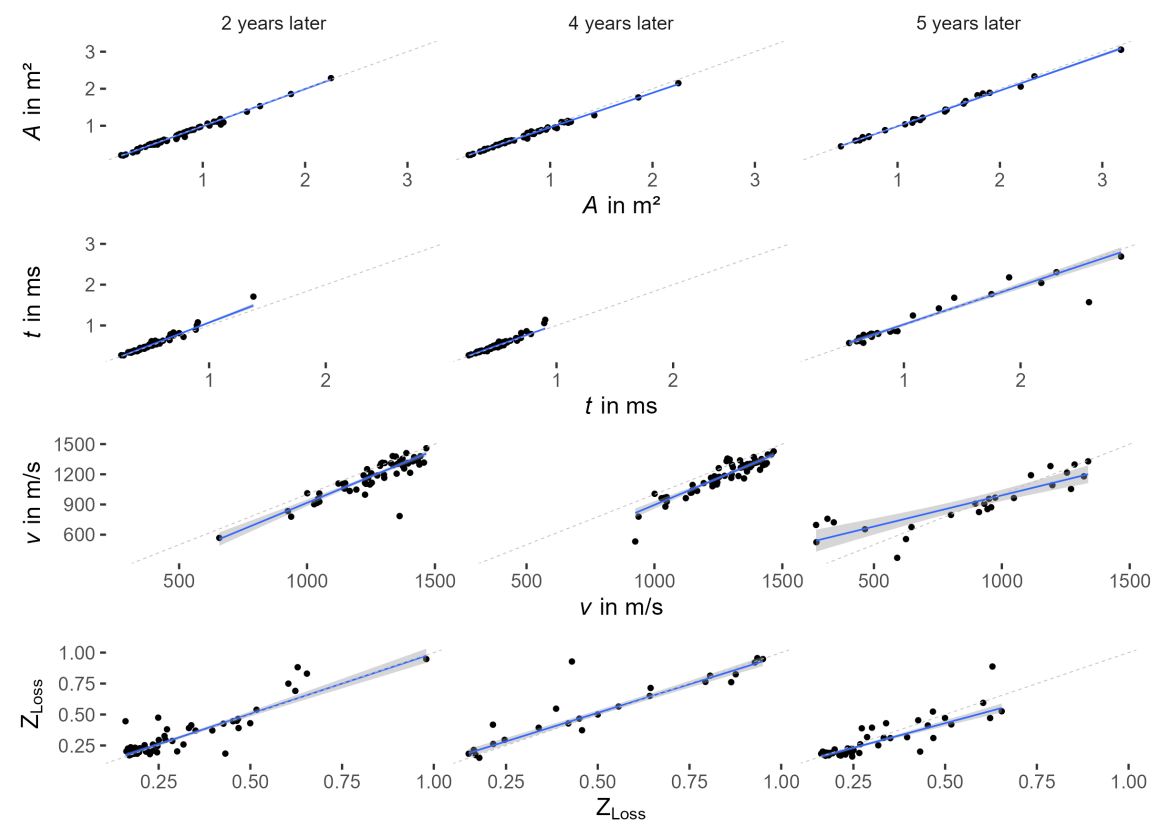

Figure 2. Correlation of initial and follow-up measurement of $t, A, v$ and $Z_{\text {Loss }}$. Tomography was repeated after 2 and 4 years at site KF and after 5 years at site TG. Dashed line indicates 1:1. Gray: $95 \%$ confidence interval.

Mean stress-wave velocity in beech was significantly higher than in all other species (Figure 4), while variation was highest in spruce.

The stress wave velocity at the edge of stem cross-sections was not significantly correlated with mean air temperature in the range of -1.5 to $22.6{ }^{\circ} \mathrm{C}(p=0.07$, Figure 5$)$. 


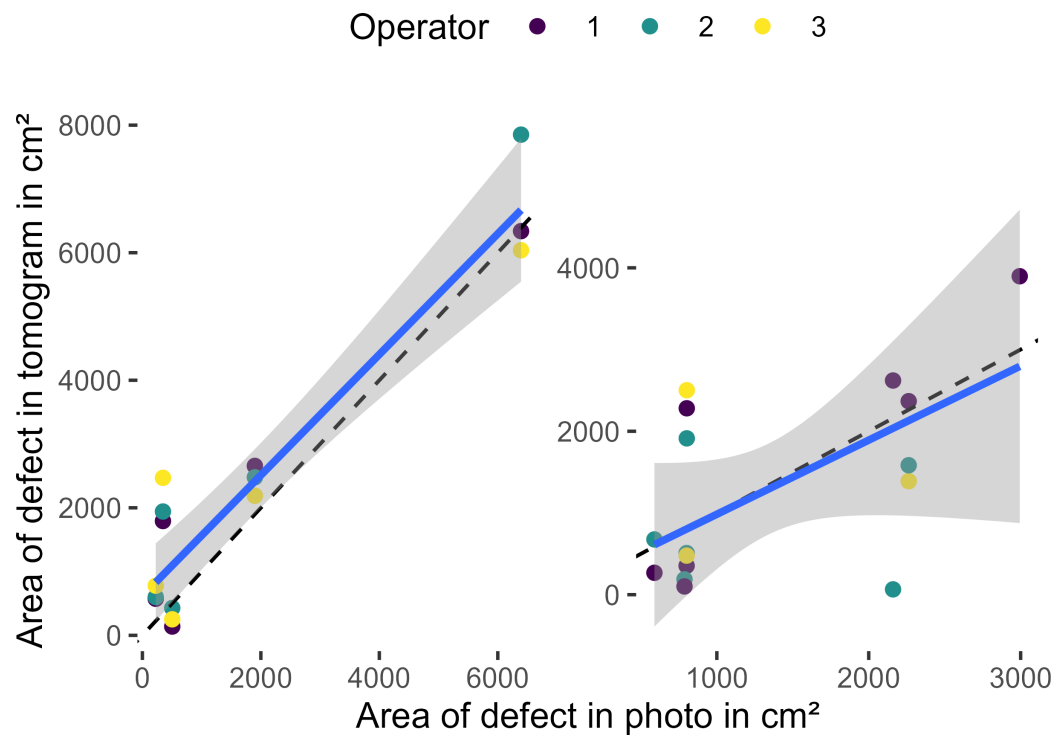

Figure 3. Correlation of defect in tomograms and images of stem cross-sections (left: site PA2, operators used the same nails; right: site AP, operators used different nails at new locations). Dashed line indicates 1:1. Gray: $95 \%$ confidence interval.

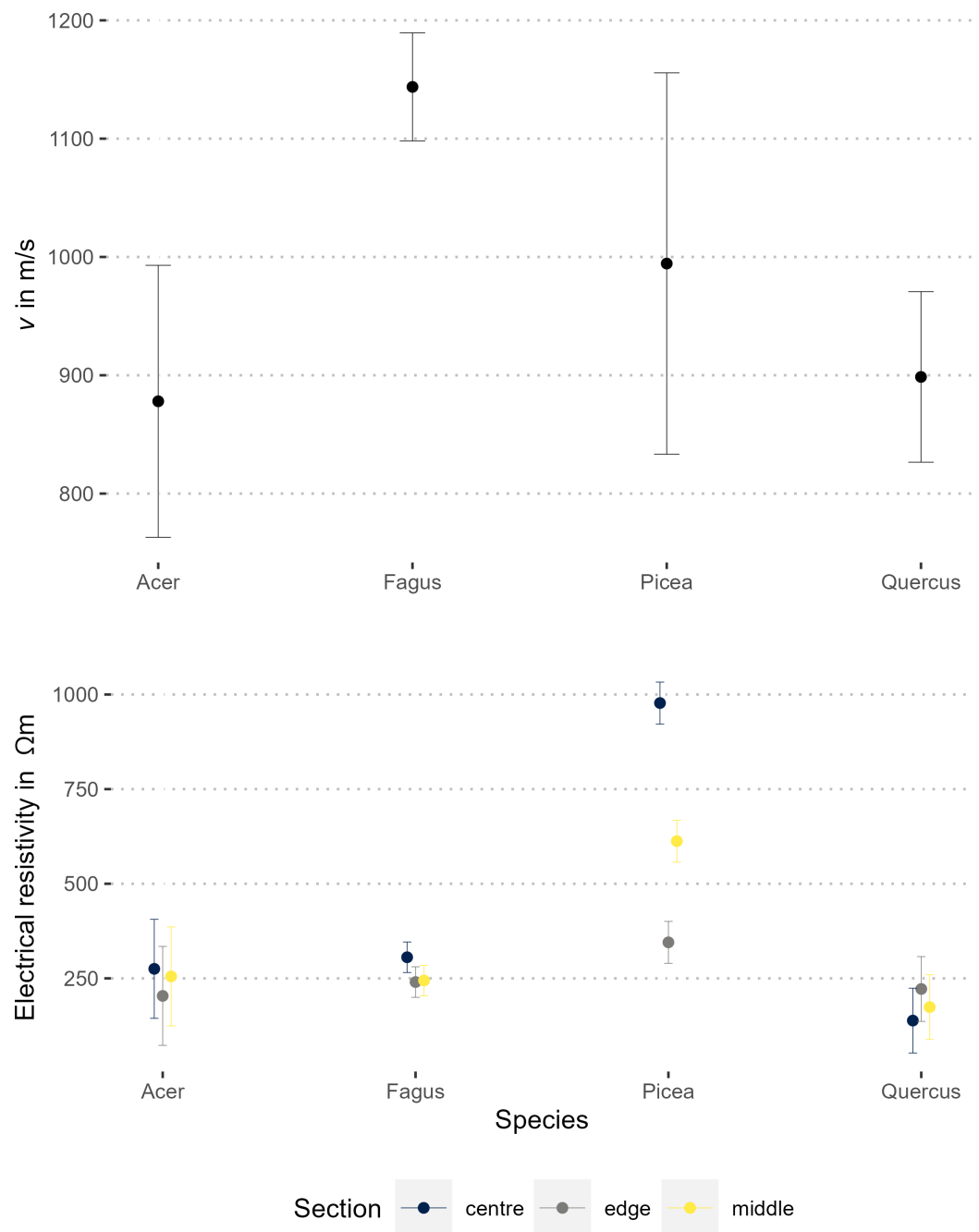

Figure 4. Species differences in stress wave velocity (top) and electrical resistivity (bottom, areaweighted median). "centre" refers to the innermost third of the stem cross-section, "edge" to the outermost third, while "middle" refers to the remainder. 


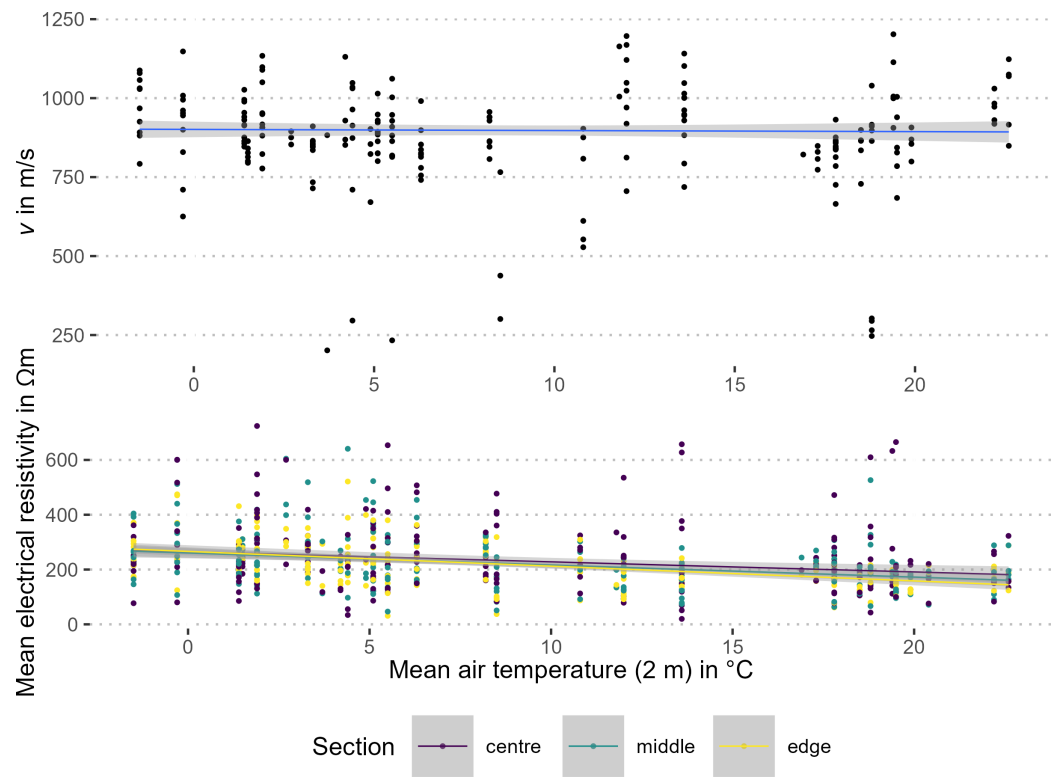

Figure 5. Correlation of tangential stress wave velocity (top), electrical resistivity ((bottom), areaweighted median), and air temperature (site KF). "centre" refers to the innermost third of the stem cross-section, "edge" to the outermost third, while "middle" refers to the remainder. Tomography was repeated for 4 years at site KF by different operators placing new sensor positions. Gray: $95 \%$ confidence interval.

\subsection{Electrical Resistivity Tomography}

Results of ERT were reproducible when repeated during a day or several times within a year (Figure 6), even if measured by different brands of tomographs. Both, after 2 and 4 years, electrical resistivities correlated well with original data $((0.72 \leq r \leq 0.73)$, Figure 7$)$. However, coefficients of correlation were lower than for SoT.

$\rho$ decreased significantly with rising air temperature (Figure 5). The effect was strongest in the wood close to the cambium. Even within one day, there were small but significant differences. After accounting for individual differences between trees and cross-section geometry, the mean resistance decreased by $2 \%$ from 8 in the morning until noon (linear mixed-effects model, $p<0.001$, Figure 8). However, effects on final tomograms were barely visible (Figure 6).

Estimates of sapwood area of spruce were stable throughout the growing season, although one tree differed in sapwood area by more than $20 \%$ between measurements, two further trees varied by more than 10\% (Figure 9).

Tree 1
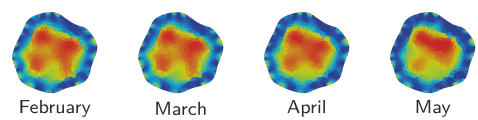

Tree 2
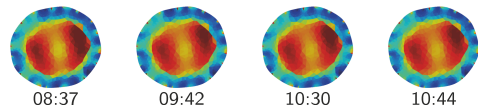
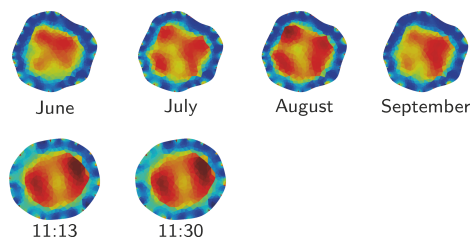

Figure 6. ERT of two spruce trees measured several times in 2021 (top) and on one day in July (bottom), site PA1. Top row: every second measurement with Geotom, all else with Picus Treetronic. 


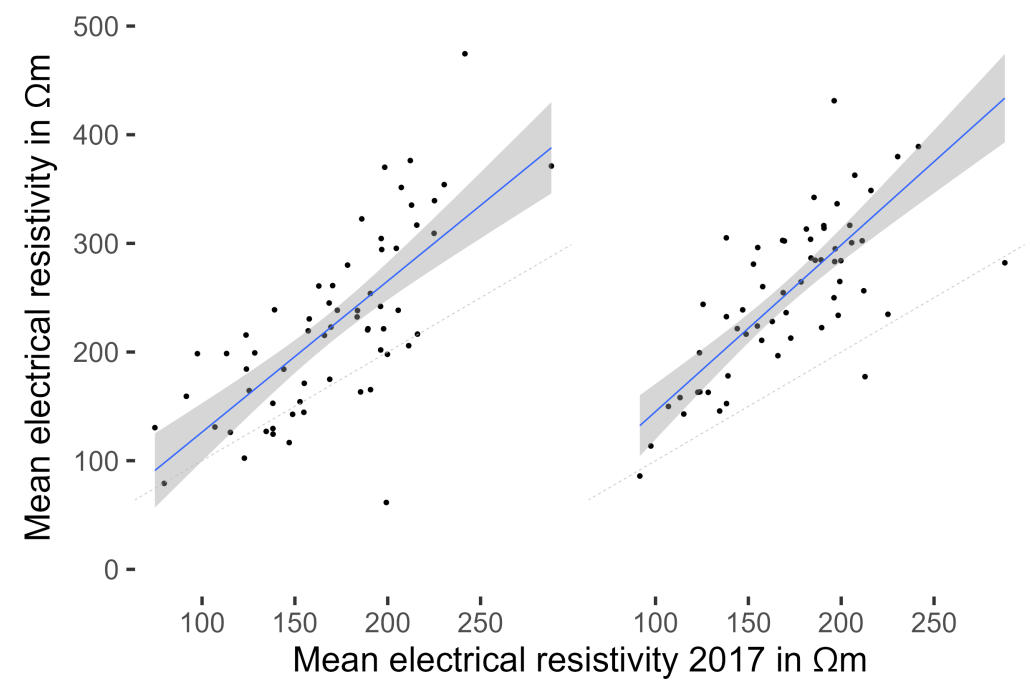

Figure 7. Correlation of initial and follow-up measurement of $\rho$. Tomography was repeated after 2 (left), and 4 (right) years at site KF by different operators placing new sensor positions. Here, $\rho$ is the area-weighted median of the outermost $33 \%$ of the stem cross-section. Dashed line indicates 1:1. Gray: $95 \%$ confidence interval.

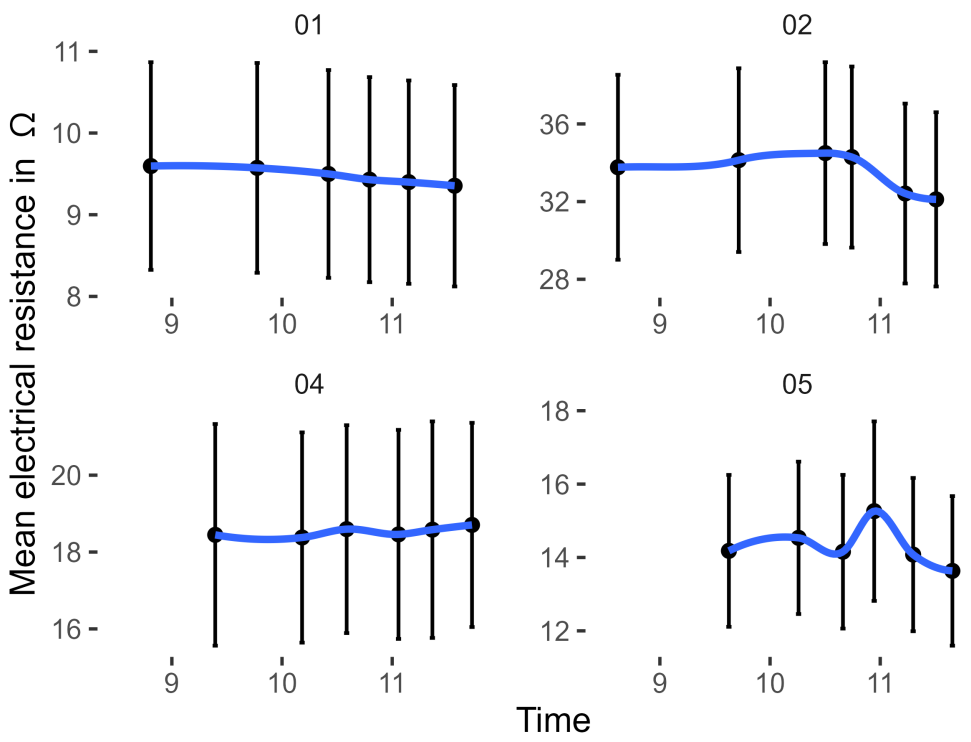

Figure 8. Course of $\Omega$ from 8 o'clock until noon in four P. abies. Mean and standard error. Site PA1.

Only spruce differed significantly in $\rho$ from all other species (Figure $4, p<0.001$ ). In this species, central areas of the stem had a fourfold higher $\rho$ than other species or the peripheral part of the stem of spruce.

There were no significant differences in $\Omega$ and hence $\rho$ between different ERT-devices. 


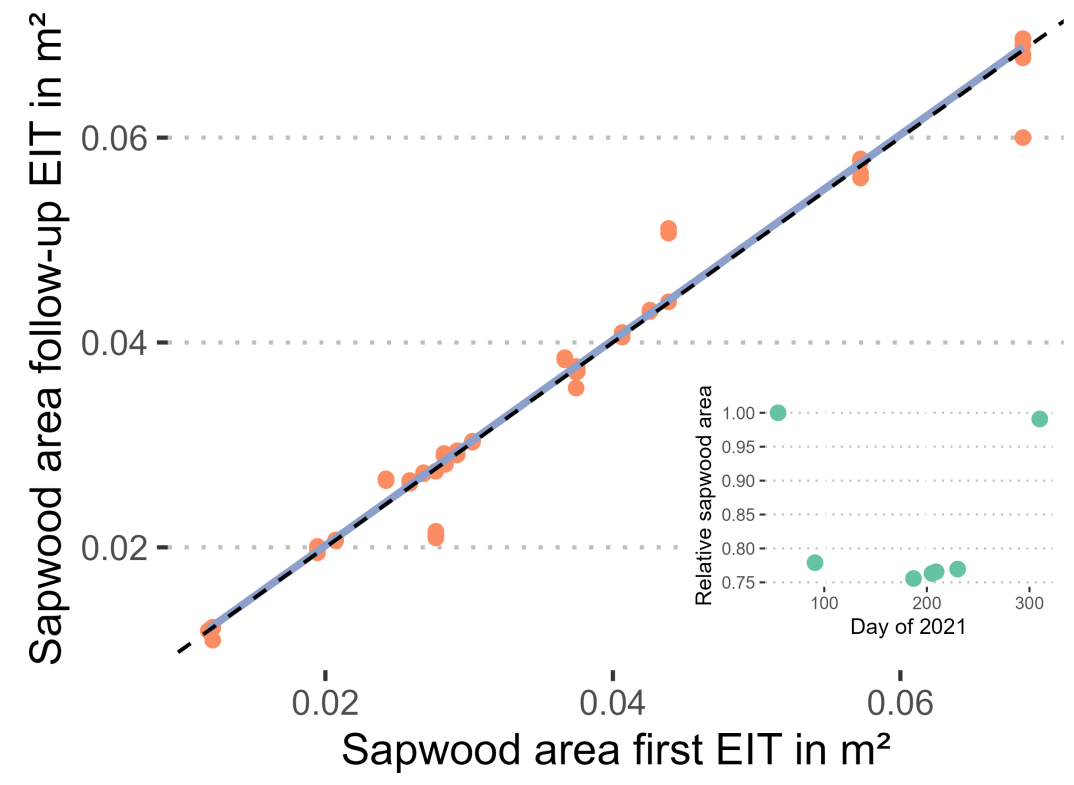

Figure 9. Sapwood area of 20 spruce trees measured several times in 2021 (site PA1, including only measurements with Picus TreeTronic). Inset shows variation of sapwood area in one individual tree with the largest changes in the sample. Blue: Linear Regression, gray: 95\% confidence interval, dashed: $1: 1$.

\section{Discussion}

When tree assessors or scientists repeat a tomographic measurement on a tree, they need to be able to differentiate between variation caused by the process of measuring and processing the data, and changes that can be attributed to spreading decay or experimental treatments. To date, the few longitudinal studies reporting repeated tomography on trees have interpreted differences between tomograms mainly as treatment effects ([32-34], but see $[11,17,35])$.

This study analyzed tomograms repeated within minutes or after several years, by the same or different operators, using either the same or a different experimental setup varying the sensor positions or the tomograph.

Stress wave tomograms were comparable even when measured by different operators some years apart. Thus, they typically allow monitoring the progress of decay, especially when SoT and ERT are combined [6]. In general, variation between repeated measurements increased with every computational step from raw data to tomograms, and was highest in parameters based on decayed area and section modulus. While measures of decayed area accumulate variation from time-of-flight, distance between sensors, and shape of the cross-section, loss of section modulus $\left(Z_{\text {Loss }}\right)$ is derived from the ratio of two parameters, accumulating all these sources of variation to the third power (Equations (1)-(4)). This propagation of variation is further illustrated in Figure 10. Even for a perfectly round tree with a perfectly round central cavity, length measurements with a standard deviation of $10 \%$ result in a standard deviation of $25 \%$ in $Z_{\text {Loss }}$.

Between repeated measurements, the change in mean $Z_{\text {Loss }}$ per site ranged from $-23 \%$ to $+7 \%$. Although overall, section modulus decreased with time as would be expected, especially, when the initial $Z_{\text {Loss }}$ was large, even large positive gains in section modulus were recorded after 5 years of advancing decay (Figure 11). Because trees cannot repair decay and diameter increment was very low in these old trees, some of these results must be wrong and illustrate the potential impact of apparently small variation of raw data on highly aggregated parameters like $Z_{\text {Loss }}$. 


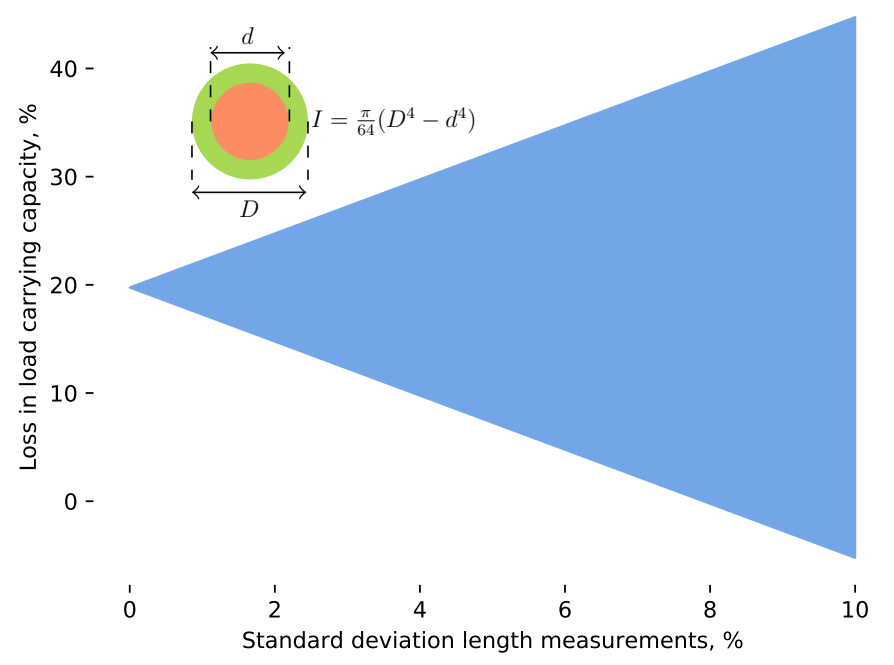

Figure 10. Effect of variation in length measurements on the standard deviation of $Z_{\text {Loss }}$ (blue area). Assumptions: Diameter of cross-section $D 1 \mathrm{~m}$, diameter of cavity $d 0.7 \mathrm{~m}$. I: Second moment of area (Equation (2)).

At temperatures above freezing, stress wave velocity is not statistically significantly affected by temperature change. This agrees with previous studies [14,16,36-41]. Only well below freezing, when the stem or parts of it are frozen, velocity increases and affects SoT [42]. And unlike ERT, SoT is very unlikely to be affected by changing wood moisture content, because reported variation of stress wave velocity above the fibre-saturation point is generally very low $[15,40,41,43-45]$, especially when compared to effects of wood decay. Therefor, differences in wood moisture content and wood temperature are unlikely to have contributed to the variation in the tomograms.

It is likely that the main source of variation in SoT is the operator. When SoT was repeated immediately by different operators using the same or different nails and positions, $v$ changed by up $5 \%$. This was caused by differences in sensor distance $d(\leq 1 \%$ change) and time-of-flight $t$ ( $\leq 6 \%$ change). Sensor distance was measured manually with an electronic caliper and therefor varied between operators due to individual levels of accuracy. Time-offlight $t$ depends to a small degree on the force of excitation [46] and is also influenced by the individual operator. For the practical application of SoT in tree risk assessment is important to note that the end product of the method, the area of defects, was not significantly affected by the operator.

Stress-wave velocity $v$ in beech was statistically significant higher than in the other species $(p<0.0001)$, which did not differ from each other. Most trees had decay, cavities, and cracks in their stems, so that these data might not be representative for the species.

$\rho$ and ERT based on it were less repeatable than $v$ and SoT. Most likely, varying wood moisture and temperature contributed to this difference. Temperature changes affected $\rho$ well above $0{ }^{\circ} \mathrm{C}$ (Figure 5), as has already been reported in earlier studies [17,18,35,47-49]. Changing irradiation on the stem, and changing stem and sap temperatures, can all cause variability in $\rho$ at the stem surface and in sap wood. Changes in stem water content during transpiration are a further source of variation [33], although they are unlikely to affect tomograms of urban trees visibly. Ref. [19] reported 5\% variation in the resistivity between successive measurements, somewhat more than the $2 \%$ found in the present study. However, centering the data of each tomogram before further processing [50] eliminated the correlation with temperature completely (data not shown) and is highly recommended when comparing ERT over time. 
In spruce, dry heartwood contributed significantly to variation in $\rho$. This is typical for many temperate conifer species and has been used to measure heartwood area [3,51,52]. $\rho$ of the hardwood species in this study was rather homogeneous.

It is important to note, that it is inherent to the process of inversion that the absolute values assigned to a triangle of the mesh are affected by the choice of parameters and thus are less stable than the ratios between all values assigned to the mesh. Lastly, changes in ERT often indicate advancing decay and tend to precede changes in SoT. Thus, they should not be treated as error without further investigation.

The small but significant effects of temperature on ERT that are reported here and have been shown in earlier studies [17,18,35,47-49], although relevant for scientific applications of ERT, affected resulting tomograms only marginally. Thus, ERT can be applied by tree assessors together with SoT, as long as temperatures are well above freezing.

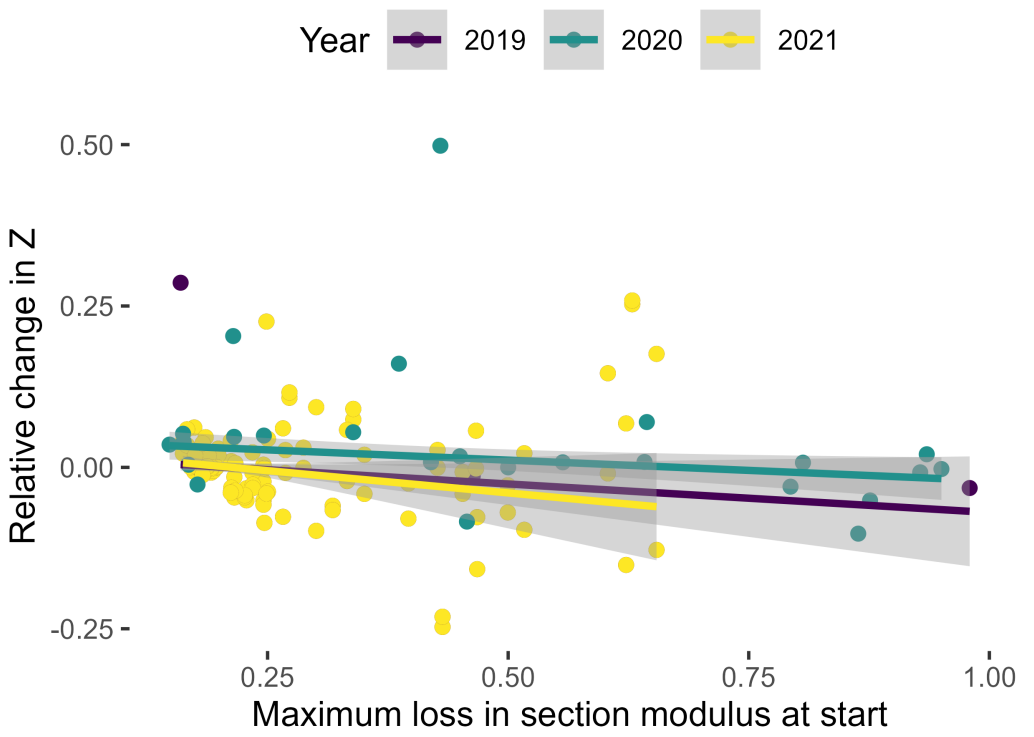

Figure 11. Correlation of initial $Z_{\text {Loss }}$ and its changes at follow-up measurements. Tomography was repeated after 2 (2019), 5 (2020) and 4 (2021) years at sites TG and KF by different operators placing new sensor positions. Gray: $95 \%$ confidence interval.

Contrary to findings by [17], long-term installation in P. abies did not affect ER tomograms.

Assessing the quality of tomograms by comparing them to photographic images has proven difficult. Without the assistance of other devices, in this study a penetrometer, the visual delineation of decay in the image is error-prone, as is the necessarily somewhat arbitrary color threshold in the tomogram used to estimate $Z_{\text {Loss }}$.

Judged by the tomograms, the spread of decay after 2 to 5 years was low for most trees. While the progress of decay has been extensively studied in vitro [53], much less is known about the speed at which fungi decay standing urban trees [54], so these results at least indicate a time-frame for follow-up measurements for tree risk assessment. Tomography, and especially the combination of SoT and ERT, is an excellent tool for further non-destructive studies in this field. They would supply tree assessors with much-needed information to decide on the intervals between successive advanced tree assessments.

As long as wood is not frozen, large differences in stem surface temperature are absent (for ERT), sensor positions are recorded and documented precisely, and previous sensor positions are re-used, results of follow-up measurements can safely be interpreted in terms of progress of decay. Although changing sensor positions should in theory not affect tomograms, it will complicate the interpretation of differences between measurements. When repeating a measurement, tree assessors should therefor try to use the same sensor 
positions whenever possible. Complex derived parameters like loss of load bearing capacity $Z_{\text {Loss }}$ should be interpreted with great caution, because of their amplified uncertainty.

Within these limitations, results should increase confidence in tomographic measurements.

Funding: This research received no external funding.

Data Availability Statement: Data are not publicly available due to legal and privacy issues.

Acknowledgments: The cities of Hannover and Göttingen, as well as the Forest Cooperative Geismar made this study possible by providing access to trees. Several students provided data measured under the supervision of the author.

Conflicts of Interest: The author declares no conflict of interest.

\section{Abbreviations}

The following abbreviations are used in this manuscript:

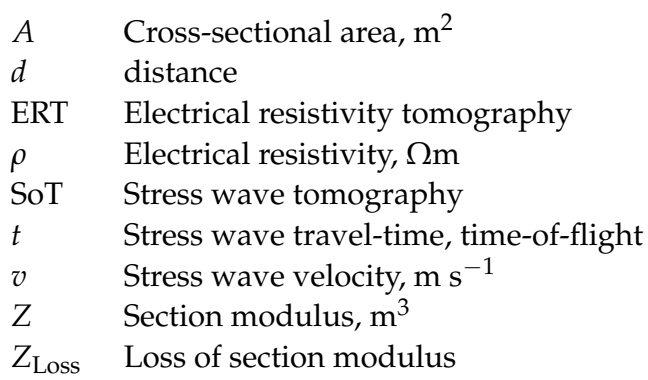

\section{Appendix A}

Summaries of statistical analyses. Model estimates and 95\% confidence intervals. Significant effects are indicated by asterisks: ${ }^{* *} p<0.01$; $^{* *} p<0.05$; ${ }^{*} p<0.1$.

Table A1. Statistical analysis of data presented in Figure 2.

\begin{tabular}{cc}
\hline & $\begin{array}{c}\text { CSA 2021 } \\
\text { Generalized Least Squares }\end{array}$ \\
\hline CSA 2017 & $0.928^{* * *}(0.907,0.948)$ \\
Constant & $0.023^{* * *}(0.006,0.040)$ \\
$\mathrm{N}$ & 54 \\
\hline
\end{tabular}

Table A2. Statistical analysis of data presented in Figure 2.

\begin{tabular}{cc}
\hline & $\begin{array}{c}\text { CSA 2020 } \\
\text { Generalized Least Squares }\end{array}$ \\
\hline CSA 2015 & $0.970 * * *(0.946,0.995)$ \\
Constant & $0.015(-0.011,0.041)$ \\
$\mathrm{N}$ & 29 \\
\hline
\end{tabular}

Table A3. Statistical analysis of data presented in Figure 2.

\begin{tabular}{cc}
\hline & $\begin{array}{c}\text { Time-of-Flight } \\
\text { Linear Mixed Effects }\end{array}$ \\
\hline Year 2019 & $0.0001^{* * *}(0.00004,0.0001)$ \\
Year 2021 & $0.0001^{* * *}(0.0001,0.0001)$ \\
Y & $0.001^{* * *}(0.001,0.001)$ \\
Year 2019:d & $0.0002^{* * *}(0.0002,0.0003)$ \\
Constant & $0.0002^{* * *}(0.0002,0.0003)$ \\
$\mathrm{N}$ & $0.001^{* * *}(0.001,0.001)$ \\
\hline
\end{tabular}


Table A4. Statistical analysis of data presented in Figure 2.

\begin{tabular}{cc}
\hline & $\begin{array}{c}\text { Time-of-Flight } \\
\text { Linear Mixed Effects }\end{array}$ \\
\hline Year 2020 & $-0.00004^{* *}(-0.0001,-0.00000)$ \\
Y & $0.002^{* * *}(0.001,0.002)$ \\
Coar 2020:d & $-0.0004^{* * *}(-0.0005,-0.0003)$ \\
$\mathrm{N}$ & $0.001^{* * *}(0.001,0.001)$ \\
\hline
\end{tabular}

Table A5. Statistical analysis of data presented in Figure 2.

\begin{tabular}{cc}
\hline & Velocity \\
& Linear Mixed Effects \\
\hline Year 2019 & $-83.843^{* * *}(-90.023,-77.663)$ \\
Year 2021 & $-82.239^{* * *}(-88.714,-75.764)$ \\
Y & $385.596^{* * *}(371.721,399.472)$ \\
Year 2019:d & $-116.463^{* * *}(-134.705,-98.221)$ \\
Constant & $-143.544^{* * *}(-162.900,-124.187)$ \\
$\mathrm{N}$ & $1196.230^{* * *}(1153.759,1238.701)$ \\
\hline
\end{tabular}

Table A6. Statistical analysis of data presented in Figure 2.

\begin{tabular}{cc}
\hline & Velocity \\
& Linear Mixed Effects \\
\hline $\mathrm{d}$ & $-288.695^{* * *}(-308.006,-269.384)$ \\
Year 2020 & $-77.531^{* * *}(-104.349,-50.713)$ \\
$\mathrm{d}:$ Year 2020 & $61.460^{* * *}(36.516,86.404)$ \\
Constant & $1178.768^{* * *}(1087.910,1269.626)$ \\
$\mathrm{N}$ & 10,017 \\
\hline
\end{tabular}

Table A7. Statistical analysis of data presented in Figure 2.

\begin{tabular}{cc}
\hline & $\begin{array}{c}Z_{\text {Loss }} \\
\text { Linear Mixed Effects }\end{array}$ \\
\hline Constant & Lin \\
$\mathrm{N}$ & $0.344^{* * *}(0.298,0.389)$ \\
\hline
\end{tabular}

Table A8. Statistical analysis of data presented in Figure 2.

\begin{tabular}{cc}
\hline & $Z_{\text {Loss }}$ \\
& Linear Mixed Effects \\
\hline Year & $0.008(-0.001,0.017)$ \\
Constant & $-15.038(-33.223,3.148)$ \\
$\mathrm{N}$ & 51 \\
\hline
\end{tabular}

Table A9. Statistical analysis of data presented in Figure 3.

\begin{tabular}{cc}
\hline & $\begin{array}{c}\text { Decay in Tomogram } \\
\text { Linear Mixed Effects }\end{array}$ \\
\hline Operator 2 & $360.228(-260.478,980.935)$ \\
Operator 3 & $45.803(-574.904,666.509)$ \\
Site PA & $1042.200(-236.794,2321.193)$ \\
Operator 2:Site PA & $-1179.744(-2737.216,377.729)$ \\
Operator 3:Site PA & $-543.753(-2621.287,1533.780)$ \\
Constant & $1962.491 * *(159.324,3765.658)$ \\
$\mathrm{N}$ & 33 \\
\hline
\end{tabular}


Table A10. Statistical analysis of data presented in Figure 4.

\begin{tabular}{cc}
\hline & Velocity \\
& Linear Mixed Effects \\
\hline Species Fagus & $101.765(-27.576,231.106)$ \\
Species Picea & $-6.438(-212.318,199.443)$ \\
Species Quercus & $75.431(-66.245,217.107)$ \\
d & $5.746(-42.482,53.975)$ \\
Species Fagus:d & $254.883^{* * *}(205.903,303.862)$ \\
Species Picea:d & $188.407^{* * *}(124.049,252.765)$ \\
Species Quercus:d & $-73.114^{* * *}(-123.187,-23.040)$ \\
Constant & $873.880^{* * *}(753.399,994.362)$ \\
N & 68,451 \\
\hline
\end{tabular}

Table A11. Statistical analysis of data presented in Figure 4.

\begin{tabular}{cc}
\hline & $\mathbf{R}$ \\
& Linear Mixed Effects \\
\hline Species Fagus & $30.617(-106.249,167.482)$ \\
Species Picea & $702.369 * *(560.373,844.365)$ \\
Species Quercus & $-136.691 *(-292.989,19.606)$ \\
Section edge & $-71.491(-210.607,67.624)$ \\
Section middle & $-19.997(-159.113,119.119)$ \\
Species Fagus:Section edge & $6.014(-136.829,148.857)$ \\
Species Picea:Section edge & $-560.837 * *(-711.898,-409.776)$ \\
Species Quercus:Section edge & $154.985 *(-11.290,321.260)$ \\
Species Fagus:Section middle & $-41.345(-184.188,101.498)$ \\
Species Picea:Section middle & $-344.959 * *(-496.020,-193.898)$ \\
Species Quercus:Section middle & $55.538(-110.737,221.813)$ \\
Constant & $275.118^{* * *}(144.350,405.885)$ \\
$N$ & 984 \\
\hline
\end{tabular}

Table A12. Statistical analysis of data presented in Figure 5.

\begin{tabular}{cc}
\hline & Velocity \\
& Linear Mixed Effects \\
\hline Air temperature & $-0.678^{*}(-1.422,0.066)$ \\
Constant & $900.022 *(870.669,929.376)$ \\
$\mathrm{N}$ & 215 \\
\hline
\end{tabular}

Table A13. Statistical analysis of data presented in Figure 5 .

\begin{tabular}{cc}
\hline & $\mathbf{R}$ \\
& Linear Mixed Effects \\
\hline Section middle & $19.333^{* * *}(7.814,30.851)$ \\
Section edge & $21.844^{* * *}(10.325,33.364)$ \\
Air temperature & $-3.072^{* * *}(-3.741,-2.403)$ \\
Section middle:Air temperature & $-0.864^{*}(-1.764,0.036)$ \\
Section edge:Air temperature & $-1.552^{* * *}(-2.452,-0.652)$ \\
Constant & $248.454^{* * *}(229.677,267.231)$ \\
$\mathrm{N}$ & 648 \\
\hline
\end{tabular}

Table A14. Statistical analysis of data presented in Figure 7.

\begin{tabular}{cc}
\hline & $\mathbf{R}$ \\
& Linear Mixed Effects \\
\hline Section middle & $19.333^{* * *}(7.814,30.851)$ \\
Section edge & $21.844^{* * *}(10.325,33.364)$ \\
Air temperature & $-3.072^{* * *}(-3.741,-2.403)$ \\
Section middle:Air temperature & $-0.864^{* *}(-1.764,0.036)$ \\
Section edge:Air temperature & $-1.552^{* * *}(-2.452,-0.652)$ \\
Constant & $248.454^{* * *}(229.677,267.231)$ \\
$\mathrm{N}$ & 648 \\
\hline
\end{tabular}


Table A15. Statistical analysis of data presented in Figure 8.

\begin{tabular}{cc}
\hline & $\begin{array}{c}\mathbf{R} \\
\text { Linear Mixed Effects }\end{array}$ \\
\hline Repetition 2 & $-0.066(-0.211,0.078)$ \\
Repetition 3 & $0.234^{* * *}(0.089,0.378)$ \\
Repetition 4 & $0.552^{* * *}(0.408,0.697)$ \\
Repetition 5 & $0.814^{* * *}(0.670,0.959)$ \\
Repetition 6 & $1.000^{* * *}(0.855,1.144)$ \\
Constant & $-49.086^{* * *}(-63.570,-34.602)$ \\
$\mathrm{N}$ & 5148 \\
\hline
\end{tabular}

Table A16. Statistical analysis of data presented in Figure 9.

\begin{tabular}{cc}
\hline & Sap Wood Area \\
& Linear Mixed Effects \\
\hline Tag & $0.00000(-0.00000,0.00000)$ \\
Constant & $0.033^{* * *}(0.026,0.039)$ \\
$\mathrm{N}$ & 96 \\
\hline
\end{tabular}

Table A17. Statistical analysis of data presented in Figure 11.

\begin{tabular}{cc}
\hline & $\begin{array}{c}\text { Decay in Tomogram } \\
\text { Linear Mixed Effects }\end{array}$ \\
\hline Operator 2 & $360.228(-260.478,980.935)$ \\
Operator 3 & $45.803(-574.904,666.509)$ \\
Site PA & $1042.200(-236.794,2321.193)$ \\
Operator 2:Site PA & $-1179.744(-2737.216,377.729)$ \\
Operator 3:Site PA & $-543.753(-2621.287,1533.780)$ \\
Constant & $1962.491 *(159.324,3765.658)$ \\
$\mathrm{N}$ & 33 \\
\hline
\end{tabular}

\section{References}

1. Rust, S. A new tomographic device for the non-destructive testing of standing trees. In Proceedings of the 12th International Symposium on Nondestructive Testing of Wood, Sopron, Hungary, 13-16 September 2000; pp. 233-238.

2. Bieker, D.; Rust, S. Electric Resistivity Tomography Shows Radial Variation of Electrolytes in Quercus Robur. Can. J. For. Res. 2010, 40, 1189-1193. [CrossRef]

3. Bieker, D.; Rust, S. Non-Destructive Estimation of Sapwood and Heartwood Width in Scots Pine (Pinus Sylvestris L.). Silva Fenn. 2010, 44, 267-273. [CrossRef]

4. Bieker, D.; Kehr, R.; Weber, G.; Rust, S. Non-Destructive Monitoring of Early Stages of White Rot by Trametes Versicolor in Fraxinus Excelsior. Ann. For. Sci. 2010, 67, 210. [CrossRef]

5. Bär, A.; Hamacher, M.; Ganthaler, A.; Losso, A.; Mayr, S. Electrical Resistivity Tomography: Patterns in Betula Pendula, Fagus Sylvatica, Picea Abies and Pinus Sylvestris. Tree Physiol. 2019, 39, 1262-1271. [CrossRef] [PubMed]

6. Rust, S.; Göcke, L.; Weihs, U.; Günther, T.; Rücker, C. Combining Sonic and Electric Impedance Tomography for Nondestructive Testing of Trees. In Proceedings of the 15th International Symposium on Nondestructive Testing of Wood, Madison, WI, USA, 10-12 September 2007; Forest Products Society: Duluth, MN, USA, 2007.

7. Mattheck, C.; Bethge, K.; West, P.W. Breakage of Hollow Tree Stems. Trees-Struct. Funct. 1994, 9, 47-50. [CrossRef]

8. Kane, B.; Ryan, D.; Bloniarz, D.V. Comparing Formulae That Assess Strength Loss Due to Decay in Trees. J. Arboric. 2001, 27, 78-87.

9. Burcham, D.C.; Brazee, N.J.; Marra, R.E.; Kane, B. Can Sonic Tomography Predict Loss in Load-Bearing Capacity for Trees with Internal Defects? A Comparison of Sonic Tomograms with Destructive Measurements. Trees 2019, 33, 681-695. [CrossRef]

10. Ciftci, C.; Kane, B.; Brena, S.F.; Arwade, S.R. Loss in Moment Capacity of Tree Stems Induced by Decay. Trees 2014, 28, 517-529. [CrossRef]

11. Rust, S. Accuracy and Reproducibility of Acoustic Tomography Significantly Increase with Precision of Sensor Position. J. For. Landsc. Res. 2017, 2, 1-6. [CrossRef]

12. Newton, P.F. Quantifying the Effects of Wood Moisture and Temperature Variation on Time-of-Flight Acoustic Velocity Measures within Standing Red Pine and Jack Pine Trees. Forests 2018, 9, 527. [CrossRef]

13. Llana, D.F.; Iniguez-Gonzalez, G.; Martinez, R.D.; Arriaga, F. Influence of Timber Moisture Content on Wave Time-of-Flight and Longitudinal Natural Frequency in Coniferous Species for Different Instruments. Holzforschung 2018, 72, 405-411. [CrossRef]

14. Gao, S.; Tao, X.; Wang, X.; Wang, L. Theoretical Modeling of the Effects of Temperature and Moisture Content on the Acoustic Velocity of Pinus Resinosa Wood. J. For. Res. 2018, 29, 541-548. [CrossRef] 
15. Cristini, V.; Tippner, J.; Vojáčková, B.; Paulić, V. Comparison of Variability in Results of Acoustic Tomographs in Pedunculate Oak (Quercus Robur L.). BioResources 2021, 16, 3046-3058. [CrossRef]

16. Gao, S.; Wang, X.; Wang, L.; Allison, R.B. Effect of Temperature on Acoustic Evaluation of Standing Trees and Logs: Part 2: Field Investigation. Wood Fiber Sci. 2013, 45, 15-25.

17. Ganthaler, A.; Sailer, J.; Bär, A.; Losso, A.; Mayr, S. Noninvasive Analysis of Tree Stems by Electrical Resistivity Tomography: Unraveling the Effects of Temperature, Water Status, and Electrode Installation. Front. Plant Sci. 2019, 10, 1455. [CrossRef]

18. Yue, X.; Wang, L.; Shi, X.; Xu, M.; Zhu, Z. Investigations on the Effects of Seasonal Temperature Changes on the Electrical Resistance of Living Trees. Forests 2018, 9, 550. [CrossRef]

19. Hanskötter, B. Diagnose Fakultativer Farbkerne an Stehender Rotbuche (Fagussylvatica L.) Mittels Elektrischer Widerstandstomographie. Ph.D. Thesis, Georg-August-Universität Göttingen, Fakultät für Forstwissenschaften und Waldökologie, Göttingen, Germany, 2004.

20. Günther, T.; Rücker, C.; Spitzer, K. Three-Dimensional Modelling and Inversion of Dc Resistivity Data Incorporating Topography-II. Inversion. Geophys. J. Int. 2006, 166, 506-517. [CrossRef]

21. Rücker, C.; Günther, T.; Spitzer, K. Three-Dimensional Modelling and Inversion of Dc Resistivity Data Incorporating Topography-I. Modelling. Geophys. J. Int. 2006, 166, 495-505. [CrossRef]

22. Son, J.; Kim, S.; Shin, J.; Lee, G.; Kim, H. Reliability of Non-Destructive Sonic Tomography for Detection of Defects in Old Zelkova Serrata (Thunb.) Makino Trees. For. Sci. Technol. 2021, 17, 110-118. [CrossRef]

23. DWD. Climate Data Center. Available online: https://cdc.dwd.de/portal/ (accessed on 30 December 2021).

24. Koizumi, A.; Hirai, T.; H, T. Evaluation of the Section Modulus for Tree-Stem Cross Sections of Irregular Shape. J. Wood Sci. 2006, 52, 213-219. [CrossRef]

25. Doube, M.; Kłosowski, M.M.; Arganda-Carreras, I.; Cordelières, F.P.; Dougherty, R.P.; Jackson, J.S.; Schmid, B.; Hutchinson, J.R.; Shefelbine, S.J. BoneJ: Free and Extensible Bone Image Analysis in ImageJ. Bone 2010, 47, 1076-1079. [CrossRef] [PubMed]

26. Schindelin, J.; Arganda-Carreras, I.; Frise, E.; Kaynig, V.; Longair, M.; Pietzsch, T.; Preibisch, S.; Rueden, C.; Saalfeld, S.; Schmid, B.; et al. Fiji: An Open-Source Platform for Biological-Image Analysis. Nat. Methods 2012, 9, 676-682. [CrossRef] [PubMed]

27. Domander, R.; Felder, A.A.; Doube, M. BoneJ2-Refactoring Established Research Software. Wellcome Open Res. $2021,6,37$. [CrossRef] [PubMed]

28. R Core Team. R: A Language and Environment for Statistical Computing; R Foundation for Statistical Computing: Vienna, Austria, 2021.

29. Pinheiro, J.; Bates, D.; DebRoy, S.; Sarkar, D.; R. Core Team. Nlme: Linear and Nonlinear Mixed Effects Models. 2022. Available online: https:/ / cran.r-project.org/web/packages/nlme/nlme.pdf (accessed on 30 December 2021).

30. Pinheiro, J.C.; Bates, D.M. Mixed-Effects Models in S and S-PLUS; Statistics and Computing; Springer: New York, NY, USA; Berlin/Heidelberg, Germany, 2004.

31. Wilcox, R.R. Introduction to Robust Estimation and Hypothesis Testing; Elsevier Science \& Technology Books: San Diego, CA, USA, 2011.

32. Martin, L.; Cochard, H.; Mayr, S.; Badel, E. Using Electrical Resistivity Tomography to Detect Wetwood and Estimate Moisture Content in Silver Fir (Abies Alba Mill.). Ann. For. Sci. 2021, 78, 65. [CrossRef]

33. Losso, A.; Sailer, J.; Bär, A.; Ganthaler, A.; Mayr, S. Insights into Trunks of Pinus Cembra L.: Analyses of Hydraulics via Electrical Resistivity Tomography. Trees 2020, 34, 999-1008. [CrossRef] [PubMed]

34. Deflorio, G.; Fink, S.; Schwarze, F.W.M.R. Detection of Incipient Decay in Tree Stems with Sonic Tomography after Wounding and Fungal Inoculation. Wood Sci. Technol. 2008, 42, 117-132. [CrossRef]

35. Mares, R.; Barnard, H.R.; Mao, D.; Revil, A.; Singha, K. Examining Diel Patterns of Soil and Xylem Moisture Using Electrical Resistivity Imaging. J. Hydrol. 2016, 536, 327-338. [CrossRef]

36. Gao, S.; Wang, X.; Wang, L.; Allison, R.B. Effect of Temperature on Acoustic Evaluation of Standing Trees and Logs: Part 1-Laboratory Investigation. Wood Fiber Sci. 2012, 44, 286-297.

37. Gao, S.; Wang, X.; Wang, L. Modeling Temperature Effect on Dynamic Modulus of Elasticity of Red Pine (Pinus Resinosa) in Frozen and Non-Frozen States. Holzforschung 2015, 69, 233-240. [CrossRef]

38. Gao, S.; Wang, X.; Wang, L.; Bruce, R.B. Modeling Temperature and Moisture State Effects on Acoustic Velocity in Wood. In Proceedings of the 17th International Nondestructive Testing and Evaluation of Wood Symposium, Sopron, Hungary, 14-16 September 2011; pp. 411-418.

39. Baechle, H.; Walker, J. The Influence of Temperature on the Velocity of Sound in Green Pine Wood. Holz als Roh-und Werkst. 2006, 64, 429-430. [CrossRef]

40. Kang, H.; Booker, R.E. Variation of Stress Wave Velocity with MC and Temperature. Wood Sci. Technol. 2002, 36, 41-54. [CrossRef]

41. Llana, D.F.; Iniguez-Gonzalez, G.; Arriaga, F.; Niemz, P. Influence of Temperature and Moisture Content on Non-Destructive Measurements in Scots Pine Wood. Wood Res. 2014, 59, 769-780.

42. Rust, S. Baumdiagnose bei Frost. Grünforum LA 2003, 33, 36-38.

43. Minamisawa, A.; Ozawa, A.; Sakai, H.; Takagi, K. Moisture effects on the ultrasonic velocities in woods. In Proceedings of the IEEE Symposium on Ultrasonics, Honolulu, HI, USA, 4-7 December 1990. [CrossRef]

44. Llana, D.F.; Short, I.; Harte, A.M. Use of Non-Destructive Test Methods on Irish Hardwood Standing Trees and Small-Diameter Round Timber for Prediction of Mechanical Properties. Ann. For. Sci. 2020, 77, 62. [CrossRef] 
45. Llana, D.F.; Iniguez-Gonzalez, G.; Esteban, M.; Hermoso, E.; Arriaga, F. Timber Moisture Content Adjustment Factors for Nondestructive Testing (NDT): Acoustic, Vibration and Probing Techniques. Holzforschung 2020, 74, 817-827. [CrossRef]

46. Aurich, M. Einfluss der Klopfstärke auf die Schalltomographie. BSc Thesis, University of Applied Science and Arts, Göttingen, Germany, 2017.

47. Nursultanov, N.; Altaner, C.; Heffernan, W.J.B. Effect of Temperature on Electrical Conductivity of Green Sapwood of Pinus Radiata (Radiata Pine). Wood Sci. Technol. 2017, 51, 795-809. [CrossRef]

48. Luo, Z.; Guan, H.; Zhang, X. The Temperature Effect and Correction Models for Using Electrical Resistivity to Estimate Wood Moisture Variations. J. Hydrol. 2019, 578, 124022. [CrossRef]

49. Nursultanov, N.; Heffernan, W.J.B.; Altaner, C.; Pang, S. Anisotropic Electrical Conductivity of Green Timber within 20-90 Degrees C Temperature Range. Wood Sci. Technol. 2020, 54, 1181-1196. [CrossRef]

50. Rathai, R.S.; Rust, S. Über den Einfluss von Baumschnittmaßnahmen. AFZ-Der Wald 2013, 68, 35-36.

51. Guyot, A.; Ostergaard, K.T.; Lenkopane, M.; Fan, J.; Lockington, D.A. Using Electrical Resistivity Tomography to Differentiate Sapwood from Heartwood: Application to Conifers. Tree Physiol. 2013, 33, 187-194. [CrossRef]

52. Lin, C.J.; Chung, C.H.; Yang, T.H.; Lin, F.C. Detection of Electric Resistivity Tomography and Evaluation of the SapwoodHeartwood Demarcation in Three Asia Gymnosperm Species. Silva Fenn. 2012, 46, 415-424. [CrossRef]

53. Schwarze, F.W.M.R. Entwicklung und biomechanische Auswirkungen von holzzersetzenden Pilzen in lebenden Bäumen und in Vitro. Ph.D. Thesis, Universität Freiburg, Freiburg, Germany, 1995.

54. Deflorio, G.; Johnson, C.; Fink, S.; Schwarze, F.W.M.R. Decay Development in Living Sapwood of Coniferous and Deciduous Trees Inoculated with Six Wood Decay Fungi. For. Ecol. Manag. 2008, 255, 2373-2383. [CrossRef] 